\title{
Modelling workforce skill-mix: how can dental professionals meet the needs and demands of older people in England?
}

\author{
IN BRIEF \\ - Highlights the need to plan the future \\ dental workforce to address the needs of \\ the changing population demography. \\ - Demonstrates the benefits of using \\ skill-mix within the dental team. \\ - Raises the issue of embracing clinical \\ dental technicians within NHS dental \\ services to meet the needs of older \\ people.
}

\author{
J. E. Gallagher, ${ }^{1}$ E. R. Kleinman ${ }^{2}$ and P. R. Harper ${ }^{3}$
}

\section{VERIFIABLE CPD PAPER}

Background There is an urgent need to consider the skill-mix of the dental team to meet the oral health needs and demands of the population in general, and older people in particular. As people live longer and retain their teeth there will be a progressive change in both the volume and type of dental care required, and the demand for care. Operational research modelling provides the opportunity to examine and test future scenarios for National Health Service (NHS) care. Aim The aim of this research was to explore the required skill-mix of the dental team to meet future need and demand of older people in England to 2028 utilising operational research methods and to examine a range of future scenarios. Method $A$ three-stage computer model was developed to consider demand for dental care, workforce supply and skill-mix. First, the demand model combined population demography and a marker of oral health with attendance and treatment rates based on NHS activity data. Monte Carlo simulation was used to give an indication of the uncertainty surrounding this projected demand. Second, projections on workforce supply and other assumptions relating to clinical hours, NHS commitment and workforce whole time equivalents (WTEs) were analysed to produce a range of estimates for the current and future workforce. Third, staff skill-mix competencies were examined and the data fed into an optimisation model. Linear programming was used to give the optimal workforce makeup and predictions for workforce requirements. Five future scenarios were run from 'no skill-mix' through to 'maximum skill-mix' in the dental team, and the outputs compared. Results The results indicate that by 2028 there will be an increase in demand for care among older people of over 80\% to almost 8.8 million hours; however, Monte Carlo simulation suggests considerable uncertainty surrounding the demand model outputs with demand deviating from the average in terms of treatment hours by as much as $22 \%$. Modelling a healthcare system with 'no skill-mix' resulted in the lowest volume of clinical staff equivalents (dentists: 8,668) providing care for older people, whereas maximum skill-mix involved more staff (clinical staff $=10,337$, of whom 2,623 were dentists, 4,180 hygienist) therapists and 3,534 clinical dental technicians) if all care is provided at the relevant level of competence. Conclusion The model suggests that with widening skill-mix, dental care professionals can play a major role in building dental care capacity for older people in future. The implications for health policy, professional bodies and dental teamworking are discussed.

\section{BACKGROUND}

\section{Older people}

An ageing population, ${ }^{1}$ coupled with trends in increased tooth retention, ${ }^{2}$ will have a significant impact on the need and demand

1*King's College London Dental Institute at Guy's, King's College and St Thomas' Hospitals, Head of Oral Health Services Research \& Dental Public Health and Senior Lecturer/Hon Consultant in Dental Public Health, Denmark Hill Campus, London SE5 9RW; ${ }^{2}$ University of Southampton, Department of Mathematics Operational Research group, Highfield, Southampton S017 1BJ; ${ }^{3}$ Cardiff University, WIMCS Research Chair in Operational Research, School of Mathematics, Senghennydd Road, Cardiff CF24 4AG

${ }^{*}$ Correspondence to: Dr Jennifer E. Gallagher Email: jenny.gallagher@kcl.ac.uk

\section{Online article number E6}

Refereed Paper - accepted 22 June 2009

DOI: 10.1038/sj.bdj.2010.106

${ }^{\circledR}$ British Dental Journal 2010; 208: E6 for dental treatment among older people in the future. ${ }^{2}$ There is a need to recognise and plan for this progressive change to ensure that the diverse and increasingly complex oral health needs of older people ${ }^{3,4}$ are met appropriately. In 2005, the Department of Health commissioned a strategic review, 'Meeting the challenges of oral health for older people', which was published as a special issue of the journal Gerodontology. ${ }^{4}$ This built on the work of the British Dental Association (BDA) report 'Oral healthcare for older people: 2020 vision.? Both documents suggest the need to focus on the planning and provision of dental care for older people and outline a similar series of far reaching recommendations. These include oral health assessments, facilitating access to care and building skills and capacity through education and training so that dental professionals are equipped to provide high quality dental care for older people. This paper explores how skill-mix may contribute to the dental care of older people. Older people are defined as aged 65 years and over.

\section{Current care}

It is well accepted that general dental practitioners provide the majority of primary dental care for older people; ${ }^{3,4}$ however, it is increasingly recognised that there is a role for the specialty of special care dentistry, together with other dental specialties, in caring for individuals and groups with complex special needs, which include older people. ${ }^{5} \mathrm{~A}$ wealth of activity and treatment data from the Dental Practice Board (DPB) 
on oral healthcare provided for older people under old general dental services (GDS) contracts and old personal dental services (PDS) agreements provides important data for modelling supply. Detailed analysis of historical National Health Service (NHS) data for older people which informed this model is reported separately. ${ }^{6}$

\section{Changing skill-mix}

Reports reviewing the NHS workforce and looking to modernise NHS dentistry suggest a commitment to workforce planning and the potential benefits of optimising the skill-mix of the healthcare team. ${ }^{7-9}$ The dental team in the UK is in the process of change. ${ }^{10-12}$ The roles of the dental hygienist and dental therapist have been replaced with a new combined role of hygiene/therapy (H/T) and clinical dental technicians (CDTs) are becoming accepted as dental care professionals (DCPs). Registration of the latter group with the General Dental Council (GDC) was occurring as this study was being undertaken. ${ }^{11,13}$ Technicians have traditionally been laboratory based and legally had no patient contact in the UK. ${ }^{14}$ Given the concentration of dentures among older people, the skills of clinical dental technicians are particularly relevant to the care of older people. Evans et al. ${ }^{15}$ have recently highlighted the level of simple and routine tasks in primary dental care that hygienists and therapists can undertake and thus the potential for much greater use of a range of DCPs. ${ }^{15}$ The scope of care is still open to debate, however the GDC makes provision for extended care by DCPs provided that they have appropriate training. ${ }^{12}$

\section{Workforce planning and dentistry}

Workforce planning on its own rarely informs policy. Well publicised queues for primary dental care in England provided the impetus for an increase in workforce training numbers, ${ }^{10,16}$ supported by the Department of Health's Report of the primary care dental workforce review in England ${ }^{9}$ which was formally published following the policy announcement.

Despite the recent attention it has attracted, workforce planning is not new to the NHS and examples can be found throughout its history ${ }^{17}$ and internationally. ${ }^{18}$ Various approaches to workforce planning have developed over the years, from simplistic workforce to population ratios through to scenario modelling. ${ }^{9}$ Scenario modelling is the most sophisticated and flexible of all the approaches to workforce planning. ${ }^{19-24}$ It allows a range of future scenarios to be explored by altering key variables and assessing the impact on patient demand and workforce supply. An example of this type of modelling can be found in 'Future scenarios on dental health care $^{21}$ in the Netherlands. This complex systems dynamics model had five submodels and examined an extensive range of scenarios including the substitution of activities from dentists to hygienists.

The most recent workforce modelling for primary dental care in England provided forecasts for supply and demand expressed in terms of clinical time for dentists only. ${ }^{9}$ The model combined trend and scenario based approaches to create individual models for demand and supply through to 2021. The authors reported a shortage of 1,850 whole time equivalent (WTE) dentists in England, predicting a fall in dentists and increase in hygienists and therapists to 2021. The gap between demand and supply was predicted to increase to $21 \%$ by 2011. Subsequent policy changes included the recruitment of 1,000 extra WTE dentists as a short-term measure. ${ }^{25}$ Longerterm measures included increasing the number of dental student training places by 170 per year and to provide an additional 150 dental therapy training places from $2005 .{ }^{16}$ Further evidence around the same time suggested that the underlying shortage of dentists was in fact greater, possibly in the region of four or five thousand. ${ }^{26,27}$ This report did predict significant increases in the demand for primary dental care among older people over the periods 2001-2010 and 2011-2021 by ten-year ageband. However nationally, workforce modelling has not been repeated on a regular basis as recommended in the review. ${ }^{28}$

Dental workforce planning in Scotland has received ongoing support with several publications and a planned programme of development. ${ }^{29,30}$ They also use a combination of trend and scenario modelling to predict the characteristics of the demand dynamics for dental services. Other smaller scale examples of workforce planning for dentistry include a forecasting model developed by Try in 2000 for the BDA, ${ }^{31}$ which suggested 'too few dentists', and a study by Hornby et al. ${ }^{32}$ which explored opportunities for dental workforce development in the Midlands Strategic Health Authority. None of these reviews or studies has fully explored the range of skill-mix in the dental team.

\section{Rationale for the study}

The National Working Group on Older People has highlighted the importance of addressing the oral health needs of this section of the population. ${ }^{4}$ Operational research techniques have much to contribute to the modelling of the future healthcare skill-mix ${ }^{20,33,34}$ and can be applied to the changing area of meeting older people's dental health needs and demands. To date there has been no research using operational research techniques to examine older people's dental care services and workforce skill-mix.

\section{AIM}

The aim of this research is to explore the required skill-mix of the dental team to meet future need and demand of older people in England to 2028 utilising operational research methods, and examine a range of future scenarios.

\section{METHOD}

Data for modelling were obtained from the Dental Practice Board directly and via their website $^{35}$ and from The Information Centre, ${ }^{36}$ the Government Actuary's Department ${ }^{37}$ and the most recent UK Adult Dental Health Survey, ${ }^{2}$ together with other relevant data such as treatment times from the BDA ${ }^{38}$ and registrations of dental professionals with the General Dental Council. ${ }^{39}$

The modelling approach was developed through careful consideration of findings from the literature review, background information and primary dental care data analysis. Elements of the English ${ }^{9}$ and Scottish ${ }^{29,30}$ models, together with Powell's Intermediate Care workforce model, ${ }^{17}$ were combined with other key findings specifically relating to dentistry for older people to create a unique Monte Carlo simulation spreadsheet model with added optimisation functionality, tailored to the project objectives. The operational research models and their mathematical basis are described in detail in a parallel paper by Harper et $a l .,^{40}$ including consideration of cost effectiveness findings in relation to skill-mix. 
Following standard statistical analysis of trends in primary dental care activity, which has already been reported in detail, ${ }^{6}$ the approach involved the creation of an Excel model consisting of three sub-models relating to 'demand' for dental treatment, 'workforce supply' and 'optimisation of workforce skill-mix' (Fig. 1). The analysis of predicted demand reported was estimated to increase by $24 \% .^{6}$ The individual components of this modelling approach are briefly described below.

\section{Demand model}

The demand model combined demography (65-99 years), rates of edentulousness, patterns of dental attendance and treatment rates for older people, along with GDS treatment times (Fig. 1). Monte Carlo simulation was used to provide estimates on the uncertainty surrounding this predicted demand.

\section{Supply model}

The baseline supply of dentists in GDS and PDS in England was based on NHS data for March 2006. A forecast of future dentist numbers to 2028 involved a simple percentage increase based on the average yearly percentage increase over the previous nine years taken from the same source, taking account of the short-term recruitment drive of over 1,000 dentists and the increased dental student intake ${ }^{16,25}$ which would enter the workforce from 2009 onwards.

Estimating the current and future supply of dental hygienists and therapists working in GDS and PDS in England proved challenging, with the estimates based on GDC registrations ${ }^{39}$ and informed by the English Primary Care Workforce Review. ${ }^{9}$ Projecting the supply of dental hygienists and therapists to 2028 was complex, given the shift to dual training of therapists and hygienists for the foreseeable future. Increases in training places $(n=150)$ for therapists from 2005 were included. Future projections included the new dental hygienists/therapists, hence the sharp projected increase in therapists and the gradual decline in hygienist numbers.

The supply model included the following assumptions:

- The average percentage increase in dentists over the last nine years (excluding the significant recruitment of 1,000 additional WTE dentists and

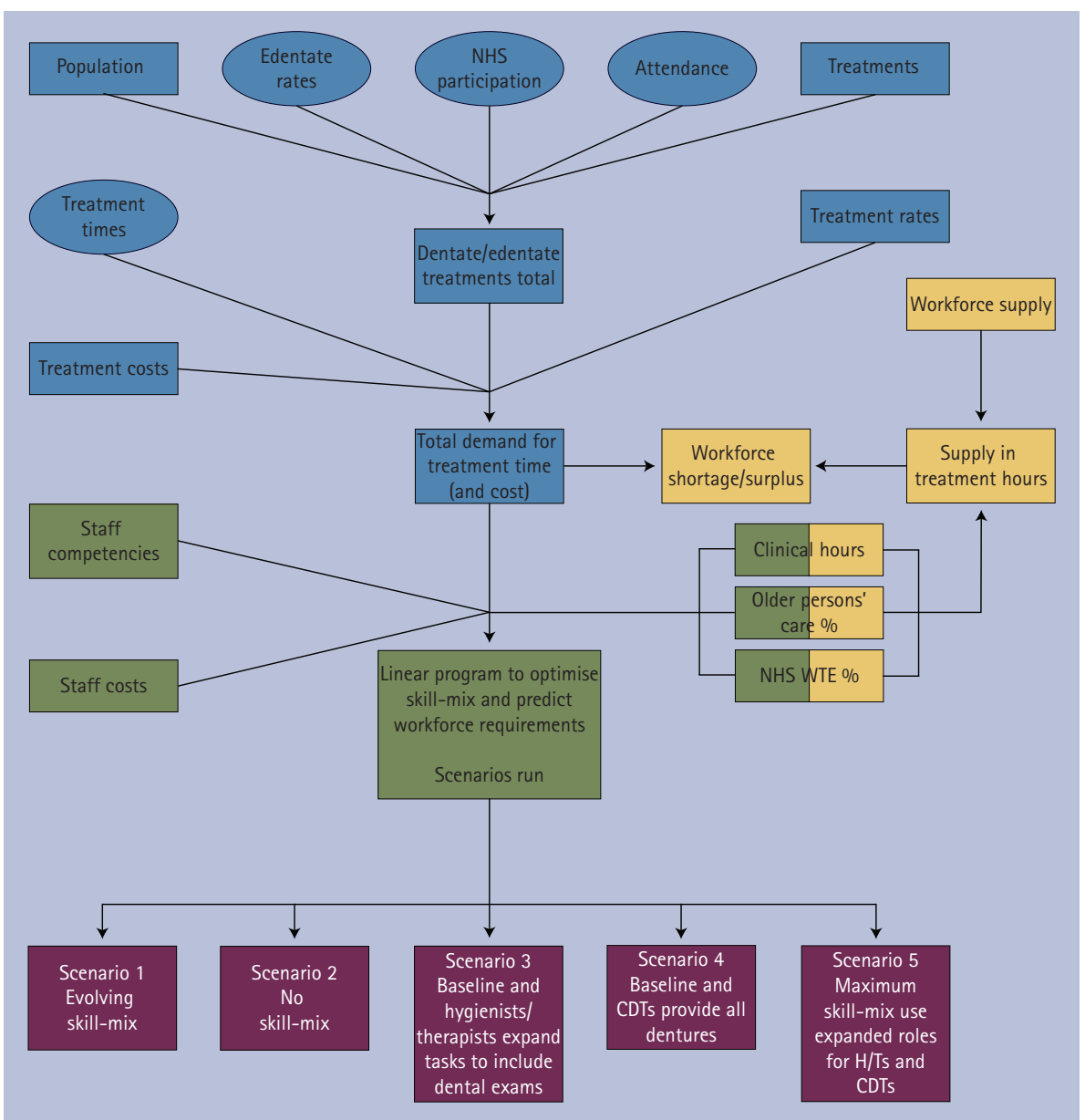

Fig. 1 Process for modeling future skill-mix for dental care of older people

170 extra dental training places) will not change significantly by 2028

- The percentage of time that dental professionals devote exclusively to treating patients aged 65 and over is proportional to the gross fees generated from treating this age group, as a proportion of total gross fees for the whole population. The proportion of dental registrations for older people is also assumed to be approximately proportional to the percentage of time devoted to treating older people

- This 'older persons' care percentage' is close to the proportion of the total population that the over $65 \mathrm{~s}$ represent, which in future years will increase significantly. Therefore the percentage of time dental professionals spend treating the older generations is expected to increase at a similar rate, especially since the oral health of the remaining adult population is expected to improve and older people are expected to need more complex treatment

- The additional 150 hygienist/therapist places were factored in with the assumption that training places will not change significantly by 2028

- The NHS WTE\% for hygienists and therapists was assumed to be $80 \%$ of the NHS WTE\% for dentists, and the supply for older persons is based on the older persons' care percentage for 2005 of 14\% based on registration and activity data

- Private care was incorporated into the model through a percentage for WTEs and NHS commitment (WTE NHS\%) which converts workforce supply into the NHS WTE supply. However the lack of concrete data on either of these parameters meant that it was not possible to confidently arrive at a single percentage value. The Primary Dental Care Review ${ }^{9}$ uses 69\% as the WTEs percentage for dentists in 2001 to convert the GDC Register headcount to the practising WTE workforce. However, this percentage allows for dentists on the register who are not currently practising as well as those working part time, whereas the workforce supply of GDS and 


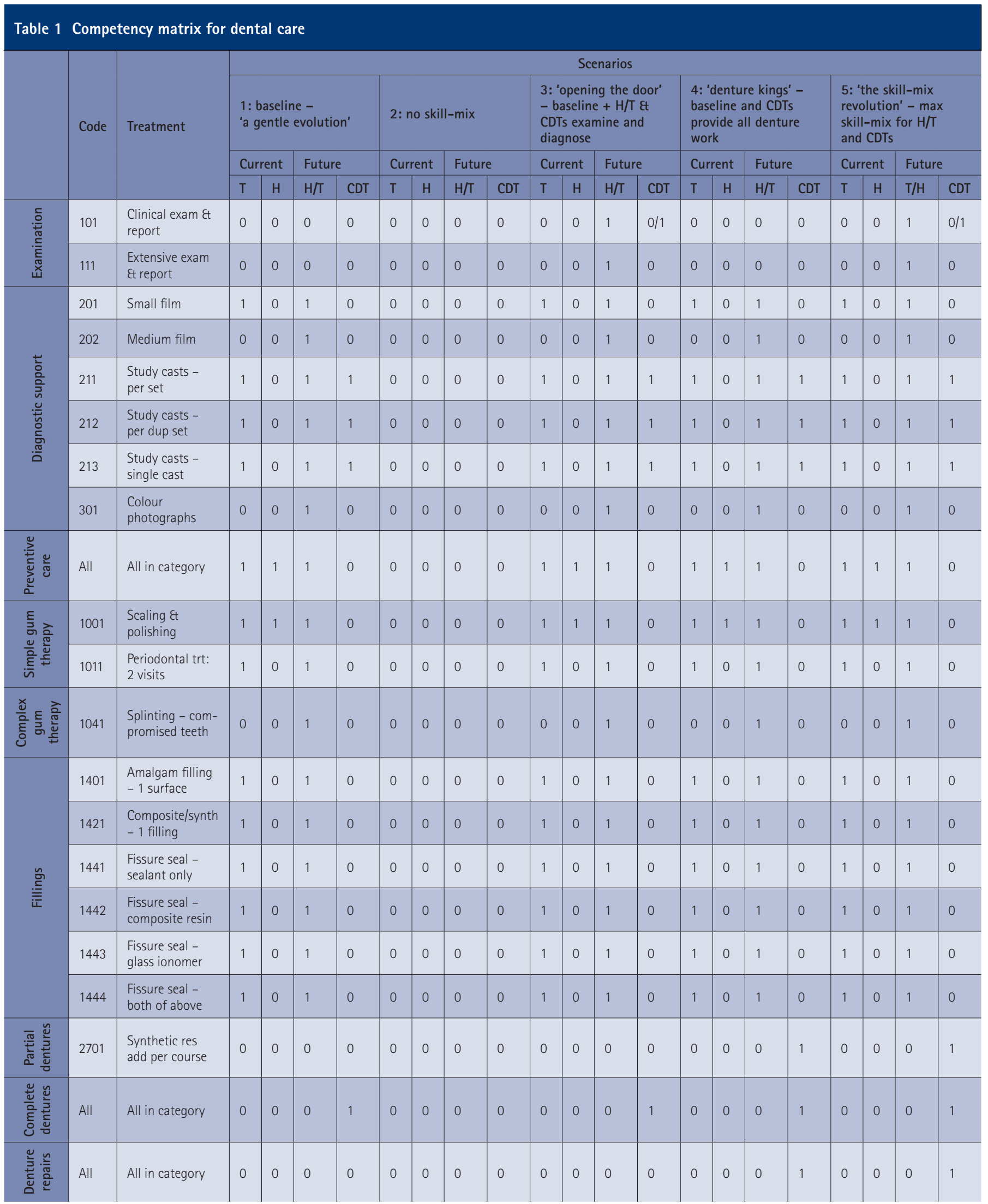

PDS dentists used in the model are all currently practising and hence the WTE percentage will be significantly higher. (Note that the Primary Care Review does not explicitly make allowances for the level of NHS commitment and hence it is assumed that it is included in the WTE percentage). Therefore it was decided that the most realistic approach would be to run several scenarios of the supply model using a range of values for the WTE NHS\% in an attempt to determine a value to be used as a baseline scenario which appears reasonable

- Finally it was necessary to incorporate the fact that the WTE NHS percentage is likely to decrease over time due 
to the projected increase in women dentists. ${ }^{41}$ The yearly percentage decrease in WTE NHS percentage $(0.5 \%)$ is based on the drop in WTEs used in the Primary Care Review. ${ }^{9}$

Projections on workforce supply and other parameters relating to clinical hours worked, level of NHS commitment and workforce WTEs were combined to produce a range of estimates for the workforce shortfall or surplus both currently and in the future.

\section{Skill-mix optimisation model}

Demand and supply data were fed into an optimisation model to provide recommendations on the composition of the optimal workforce. The model was tested and validated against the findings of other workforce studies.

\section{Scenario planning}

Five 'What if?' scenarios were run to examine the effects of varying staff competencies at key points between 2005 and 2028 as outlined in Figure 1. The DCP staff competency matrix in Table 1 illustrates which treatments staff can and cannot perform, indicated by 1 or 0 respectively, both currently and in the future for each of the scenarios tested. Dentists perform all treatments, and 'current' refers to the baseline data from 2005 while 'future' refers to 2008 onwards. All treatments belonging to care categories excluded from Table 1 are, and will continue to be, performed exclusively by dentists.

Scenario 1, the baseline, recognises that hygienists and therapists currently provide certain aspects of dental care and that clinical dental technicians will provide complete dentures, and it profiles 'evolving skill-mix'. A gap analysis against predicted supply was conducted for this baseline scenario. Scenario 2 considers a future with 'no skillmix', where dentists provide all dental care and there are no clinical DCPs. Scenario 3, The 'DCP providing front-end care' scenario entitled 'DCPs opening the door', explored H/T and CDTs providing front-end care, ie examination and diagnosis, as well as the current range of care in the baseline scenario. Scenario 4 considers 'CDTs as denture kings' providing all denture care with DCPs, building on the baseline scenario. Finally, Scenario 5, 'the skill-mix

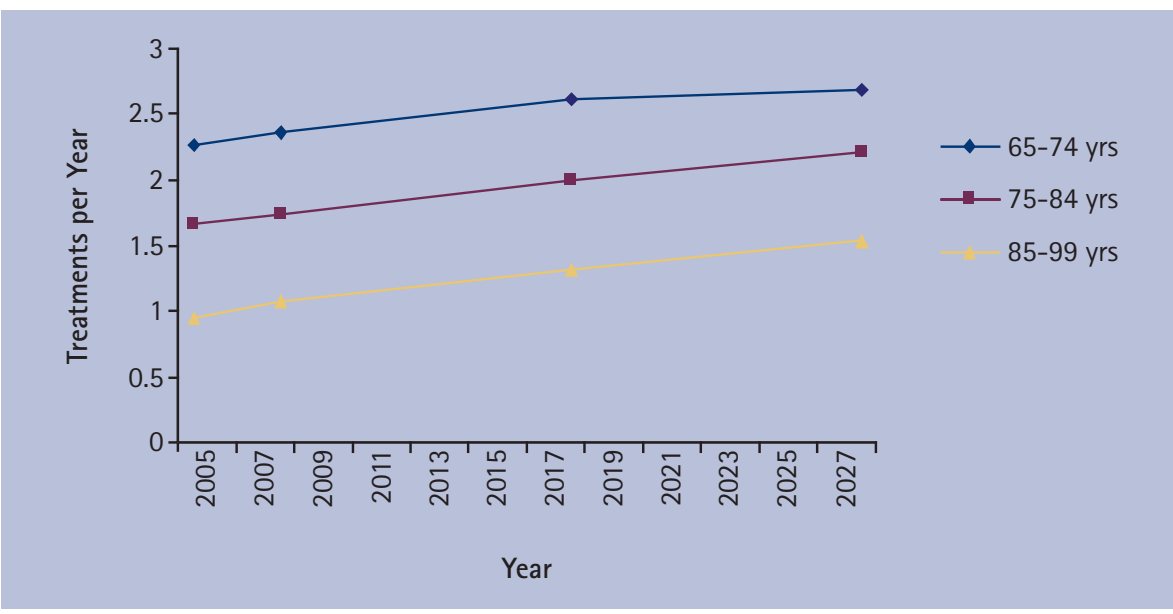

Fig. 2 Projected demand for treatments per capita

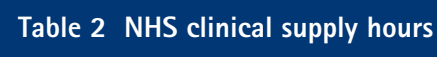

\begin{tabular}{|l|l|l|l|}
\multicolumn{2}{l}{ NHS WTE\% } & \multicolumn{2}{l}{ NHS clinical supply hours } \\
\hline Dentist & Hygienist/Therapist & Total population & Older population \\
\hline 40 & 32 & $14,223,711$ & $2,004,121$ \\
\hline 50 & 40 & $17,779,639$ & $2,505,151$ \\
\hline 60 & 48 & $21,335,567$ & $3,006,181$ \\
\hline 70 & 56 & $24,891,495$ & $3,507,212$ \\
\hline 80 & 64 & $28,447,423$ & $4,008,242$ \\
\hline 90 & 72 & $32,003,351$ & $4,509,272$ \\
\hline 100 & 80 & $35,559,279$ & $5,010,302$ \\
\hline
\end{tabular}

revolution', examines maximum skill-mix. In doing so it combines maximum use of $\mathrm{H} / \mathrm{T}$ and CDT roles within the dental team for clinical care, as well as front-end care of dental examination and diagnosis.

\section{RESULTS}

\section{Demand model}

The demand model indicates that the total number of treatments and total demand for treatment hours for older people (65-99 years) are expected to increase in absolute terms in the future given the forecasted growth in the population. While it is interesting to examine the absolute increase in treatment demand, considering the change in treatment demand per capita allows the effects of trends in increased tooth retention to be assessed in isolation from population growth. Considering the three age groups separately highlights how demand decreases with age. Figure 2 shows the increase in demand per capita across the three age-bands of older people. Currently (in 2005) the demand for clinical time for older people is estimated to be approximately 4.8 million hours and by 2028 it is expected to have risen to almost 8.8 million hours, an increase of over $80 \%$.

\section{Workforce supply model}

Due to the difficulties experienced in obtaining accurate data on the level of staff commitment to the NHS and the ratio of WTE to workforce numbers, the supply model results for NHS clinical supply hours are presented as a range based on the NHS WTE percentage. Table 2 presents the current NHS clinical supply hours for both the total population and older people only based on a range of values for the NHS WTE\%. Based on the current average demand, in order for supply to meet demand the NHS WTE\% would need to be close to $100 \%$, which is unlikely to be the case. It is also especially important to consider the 25th percentile for demand as comparison with the Primary Care Review $^{28}$ suggested that this may be closer to the true demand. 


\section{Comparison of demand and supply}

Figure 3 provides an overview of the results from the demand model compared with those from the supply model. In Figure 3 the undersupply in treatment hours is expressed as a percentage of the demand for treatment time, based on a range of values for NHS WHE. The interquartile range and the 90\% confidence intervals calculated by Monte Carlo simulation are expressed as error bars surrounding the average value of projected demand. Figure 4 combines the data from 2005 to 2028, displaying the projected under-supply in NHS WTE based on average demand and the 2005 dentists NHS WTE.

For the whole population, the current shortfall is estimated at 3,812 NHS WTE dental staff in 2005 and the shortfall is expected to peak in 2008, with a shortage of 4,018 NHS WTE dental staff forecast. By 2018 the shortfall is expected to reduce to 1,781 dental staff and by 2028 the shortfall is expected to have disappeared altogether with a surplus of 2,354 dental staff projected. Currently, and in the short-term, future demand appears to be outstripping supply despite the recent recruitment drive for dentists. However by the medium to longer term future, the planned expansion of dentist and hygienist/therapist training places and the increase in the percentage of time that dental staff devote to treating older people is expected to combine to allow the previously unmet demand to be met. It is also important to recognise the contribution of clinical dental technicians who have not been included in the analysis to this point. By 2008 it was anticipated that they will be practising and will hence help meet some of the unmet demand from 2008 onwards. By 2028 they may contribute to a workforce surplus. However it must be stressed that these results are very sensitive to assumptions and that the true outcome may lie anywhere between the 5th and 95th percentiles. It may even lie outside these bounds if other assumptions such as the NHS WTE\% vary significantly.

While there remains uncertainty surrounding the precise magnitude of the workforce shortfall, the comparison of demand and supply demonstrated that in this first decade of the 21st century there is a shortage of dental staff in England. The results suggest that in the future the shortfall is expected to decrease and will perhaps even disappear altogether.

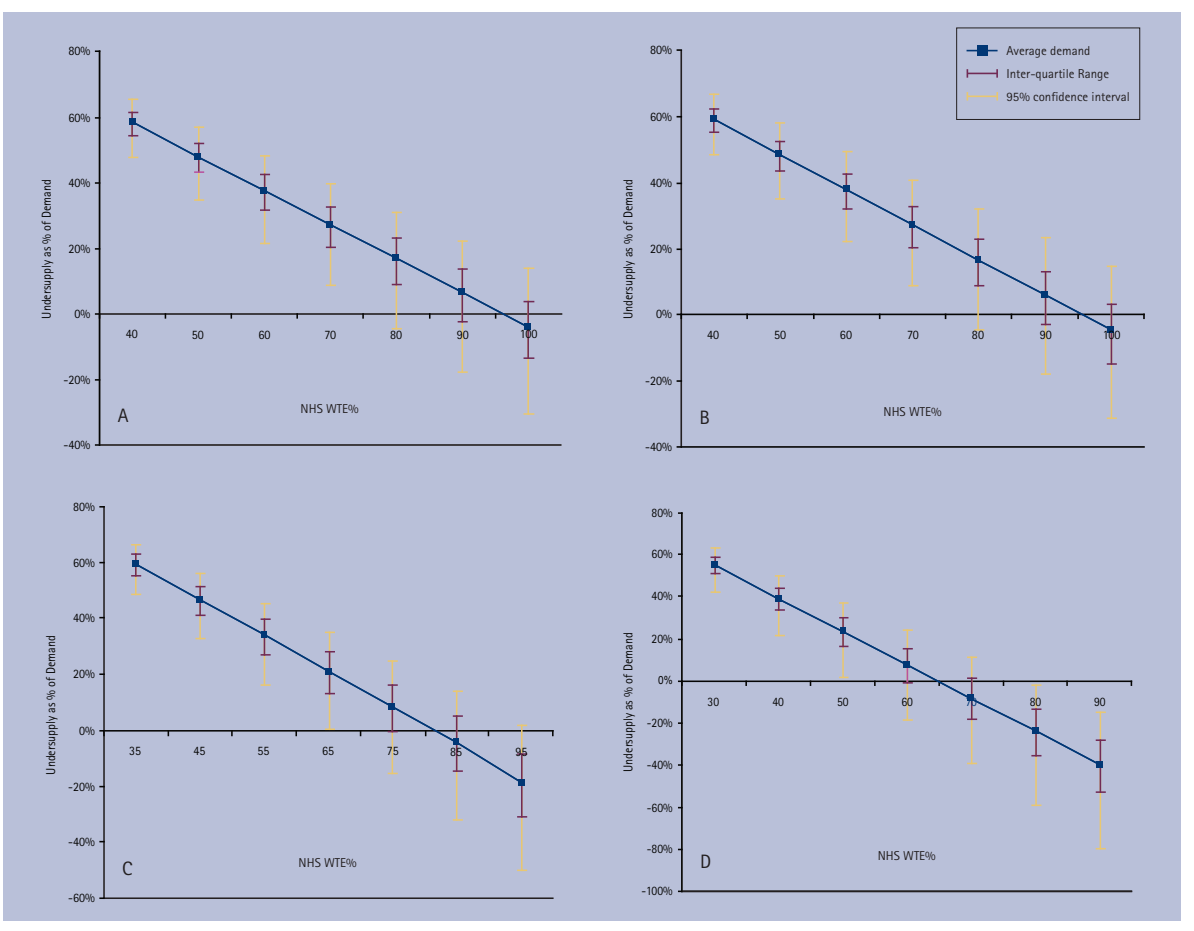

Fig. 3 Projected undersupply as a percentage of demand for a) 2005, b) 2008, c) 2018 and d) 2028

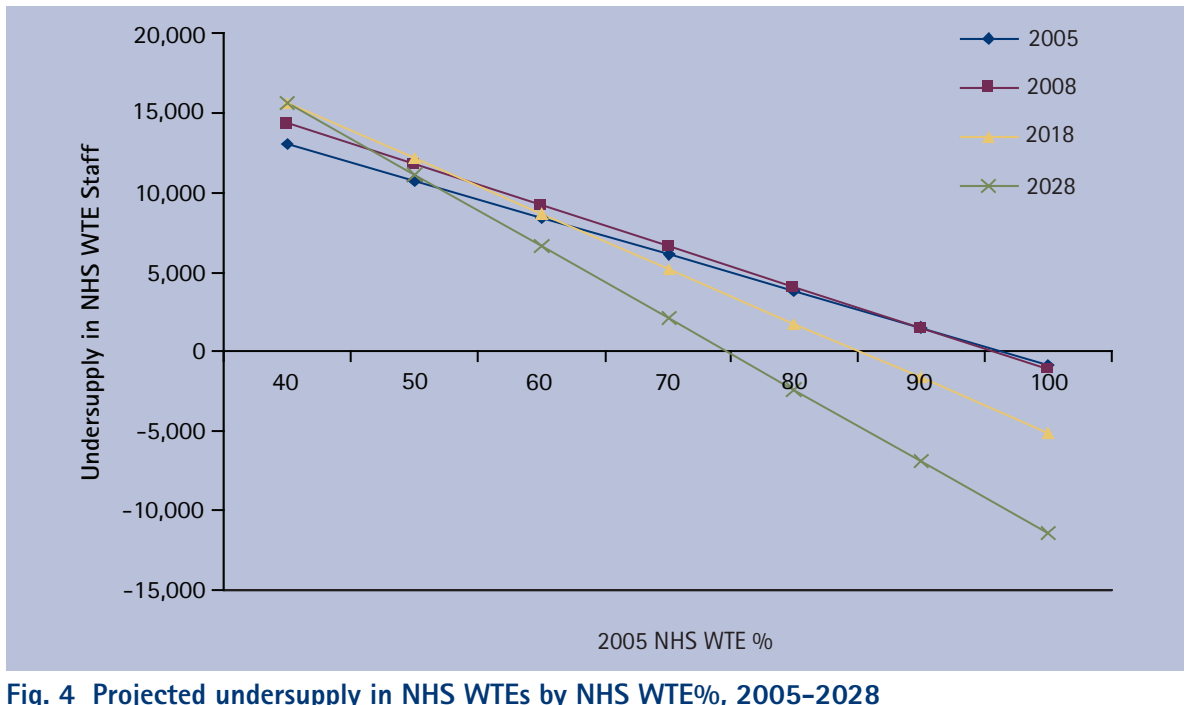

Fig. 4 Projected undersupply in NHS WTEs by NHS WTE\%, 2005-2028

\section{Skill-mix optimisation model}

The optimisation model was designed to facilitate the testing of scenarios regarding skill-mix and other factors. Therefore the results for this section are presented as a series of scenarios based on staff competencies. The results of the optimisation of the skill-mix for the five scenarios are presented in Table 3. Each scenario is now discussed in turn.

\section{Scenario 1:}

baseline 'evolving skill-mix'

Under the baseline scenario, staff competencies are based on the treatments that DCPs are currently carrying out and the treatments that they are most likely to carry out in the future.

The results of the linear program for the baseline scenario indicate that in 2005 hygienists perform all preventive care and that simple periodontal care is divided between hygienists and therapists. In the future hygienists/therapists continue providing all simple periodontal therapy and clinical dental technicians perform all complete denture work. The number of clinical dental technicians required drops in 2028 if they are only providing complete dentures due to the projected fall in edentulousness.

Comparing the workforce required by the linear program to that forecast by the 


\begin{tabular}{|c|c|c|c|c|c|c|c|c|c|c|c|}
\hline & & \multicolumn{5}{|c|}{ Total population } & \multicolumn{5}{|c|}{ Older people's care } \\
\hline & & \multicolumn{4}{|c|}{ Staff type } & \multirow{2}{*}{$\begin{array}{l}\text { Total } \\
\text { staff }\end{array}$} & \multicolumn{4}{|c|}{ Staff type } & \multirow{2}{*}{$\begin{array}{l}\text { Total } \\
\text { staff }\end{array}$} \\
\hline & & $\mathrm{D}$ & $\mathrm{H}$ & $\begin{array}{l}\text { Tor } \\
\mathrm{H} / \mathrm{T}\end{array}$ & CDT & & $\mathrm{D}$ & $\mathrm{H}$ & $\begin{array}{l}\text { T or } \\
\mathrm{H} / \mathrm{T}\end{array}$ & CDT & \\
\hline \multirow{3}{*}{$\begin{array}{l}\text { Scenario 1: baseline } \\
\text { 'A gentle evolution' }\end{array}$} & 2005 & $\begin{array}{l}21,431 \\
(19,797)\end{array}$ & $\begin{array}{l}3,975 \\
(3,577)\end{array}$ & $\begin{array}{l}4,232 \\
(537)\end{array}$ & $\begin{array}{l}0 \\
-\end{array}$ & $\begin{array}{l}29,638 \\
(23,911)\end{array}$ & $\begin{array}{l}3,020 \\
(2,789)\end{array}$ & $\begin{array}{l}560 \\
(504)\end{array}$ & $\begin{array}{l}596 \\
(76)\end{array}$ & $\begin{array}{l}0 \\
-\end{array}$ & $\begin{array}{l}4,176 \\
(3,369)\end{array}$ \\
\hline & 2008 & $\begin{array}{l}22,987 \\
(22,132)\end{array}$ & $\begin{array}{l}0 \\
(3,706)\end{array}$ & $\begin{array}{l}8,837 \\
(803)\end{array}$ & $\begin{array}{l}165 \\
-\end{array}$ & $\begin{array}{l}31,989 \\
(26,640)\end{array}$ & $\begin{array}{l}3,329 \\
(3,205)\end{array}$ & $\begin{array}{l}0 \\
(536)\end{array}$ & $\begin{array}{l}1,280 \\
(116)\end{array}$ & $\begin{array}{l}148 \\
-\end{array}$ & $\begin{array}{l}4,756 \\
(3,857)\end{array}$ \\
\hline & 2028 & $\begin{array}{l}31,011 \\
(39,790)\end{array}$ & $\begin{array}{l}0 \\
(3,914)\end{array}$ & $\begin{array}{l}12,494 \\
(2,563)\end{array}$ & $\begin{array}{l}118 \\
-\end{array}$ & $\begin{array}{l}43,624 \\
(46,268)\end{array}$ & $\begin{array}{l}6,525 \\
(8,372)\end{array}$ & $\begin{array}{l}0 \\
(824)\end{array}$ & $\begin{array}{l}2,629 \\
(539)\end{array}$ & $\begin{array}{l}107 \\
-\end{array}$ & $\begin{array}{l}9,260 \\
(9,735)\end{array}$ \\
\hline \multirow{3}{*}{ Scenario 2: no skill-mix } & 2005 & 27,619 & 0 & 0 & 0 & 27,619 & 3,891 & 0 & 0 & 0 & 3,891 \\
\hline & 2008 & 30,813 & 0 & 0 & 0 & 30,813 & 4,462 & 0 & 0 & 0 & 4,462 \\
\hline & 2028 & 41,199 & 0 & 0 & 0 & 41,199 & 8,668 & 0 & 0 & 0 & 8,668 \\
\hline \multirow{3}{*}{$\begin{array}{l}\text { Scenario 3: 'opening the front door' } \\
\text { Baseline + H/T Ct CDTs do exams }\end{array}$} & 2005 & 21,431 & 3,975 & 4,232 & 0 & 29,638 & 3,020 & 560 & 596 & 0 & 4,176 \\
\hline & 2008 & 21,194 & 0 & 10,659 & 235 & 32,089 & 3,069 & 0 & 1,543 & 212 & 4,612 \\
\hline & 2028 & 25,082 & 0 & 19,865 & 164 & 45,111 & 5,277 & 0 & 4,180 & 148 & 9,457 \\
\hline \multirow{3}{*}{$\begin{array}{l}\text { Scenario 4: 'denture kings' } \\
\text { Baseline + CDTs do all dentures }\end{array}$} & 2005 & 21,431 & 3,975 & 4,232 & 0 & 29,638 & 3,020 & 560 & 596 & 0 & 4,176 \\
\hline & 2008 & 13,387 & 0 & 8,837 & 2,111 & 24,335 & 1,938 & 0 & 1,280 & 1,900 & 5,118 \\
\hline & 2028 & 18,398 & 0 & 12,494 & 3,881 & 34,773 & 3,871 & 0 & 2,629 & 3,493 & 9,993 \\
\hline \multirow{3}{*}{$\begin{array}{l}\text { Scenario 5: 'skill-mix revolution' } \\
\text { Maximum skill-mix }\end{array}$} & 2005 & 21,431 & 3,975 & 4,232 & 0 & 29,638 & 3,020 & 560 & 596 & 0 & 4,176 \\
\hline & 2008 & 8,904 & 0 & 14,048 & 2,182 & 25,134 & 1,289 & 0 & 2,034 & 1,963 & 5,287 \\
\hline & 2028 & 12,469 & 0 & 19,865 & 3,927 & 36,261 & 2,623 & 0 & 4,180 & 3,534 & 10,337 \\
\hline
\end{tabular}

supply model we observe that the largest shortfall by far is in the supply of dental therapists/hygienists. By 2028 the linear program indicates almost a 50\% shortage in hygienists/therapists accompanied by a potential 23\% over-supply of dentists for the baseline scenario.

\section{Scenario 2: 'no skill-mix'}

The 'no skill-mix' scenario under which dentists provide all treatment is run in order to enable the full benefits of skillmix to be appreciated. This scenario actually requires a smaller dental workforce in general, and a smaller workforce for older people, than scenarios 1 and 3 . This is because dentists' working hours are longer than all dental staff.

Scenario 3: baseline + DCPs performing examinations - 'opening the door'

Under this scenario, in addition to the competencies used for the baseline scenario it is assumed that from 2008 dental hygienists/therapists will carry out routine and extensive examinations and that clinical dental technicians will perform examinations of edentate patients. An estimation of edentate examinations for each time point is taken from the demand model outputs. For the year 2005, this scenario is kept the same as the baseline scenario as it is not realistic to assume that therapists are currently performing examinations. It is also important to consider that while DCPs have (or will have) the skills to perform examinations, baseline data involved all treatment being prescribed by the dentist.

Since the optimisation aims to maximise skill-mix, the linear program determines that hygienists/therapists should perform a very high proportion of examinations. Yet examinations constitute almost a quarter of all items of care (as illustrated by the demand model) and hence the resulting number of hygienist/therapists required under the scenario appears unrealistic given the current and projected workforce make-up, which is heavily dominated by dentists. While this domination by dentists is expected to reduce in the future, the extent of the reduction is expected to be less drastic.

Results obtained from limiting the proportion of routine and extensive examinations that hygienists/therapists perform to $40 \%$ gave more reasonable results in terms of workforce make-up. The decision was not taken to limit the proportion of edentate examinations that CDTs can perform for this scenario as patients may go to them directly.

\section{Scenario 4: baseline + clinical dental technicians performing all denture work - 'CDTs as denture kings'}

The fourth scenario looks at clinical dental technicians performing all denture work, which includes partial dentures and denture repairs as opposed to only complete dentures as in the baseline scenario. As for the previous scenario, for 2005 the results from the baseline scenario are used since 
clinical dental technicians were not practising NHS care.

Under this scenario, from 2008 onwards the total workforce required is less than under all the previous scenarios. This is partly due to the fact that (it has been assumed that) clinical dental technicians will spend $90 \%$ of their time providing care for older people whereas the other staff types are estimated to spend only $14.5 \%$ and $21 \%$ of their time treating older patients in 2008 and 2028 respectively. Compared to the baseline scenario, scenario 4 highlights the importance of the introduction of clinical dental technicians to the dental workforce. Partial dentures are the element of care requiring the most treatment time (across all time points). Combined with clinical dental technicians focusing on care for older people, this suggests that the introduction of a modest number of clinical dental technicians will have a significant positive impact on the provision of dental care, for older people especially.

\section{Scenario 5: maximum s}

\section{kill-mix - 'skill-mix revolution'}

Finally the 'maximum skill-mix' scenario combines the staff competencies used in scenarios 1, 3 and 4 in order to consider the outcome should staff capabilities be used to the full. The findings suggest that if skill-mix were utilised to the full and included front-end examination and diagnosis, the shape of the dental team serving older people would involve higher numbers of hygienists/therapists $(4,180$ WTE) and clinical dental technicians (3,534 WTE) than dentists ( $\mathrm{n}=2,623 \mathrm{WTE})$ and the team overall would be largest.

\section{DISCUSSION}

\section{Limitations of the project}

Workforce modelling has many limitations. First, no modelling exercise can build an accurate picture of the present or predict the future; however, it can provide insight to help plan for possible futures. ${ }^{42}$ There is always a trade-off between model complexity to reflect the system and simplicity so that it is understandable. Second, model building is dependent upon having relevant data which are in short supply, a point which has been noted and is being addressed in Scotland..$^{30}$ Many of the assumptions are simplistic, such as the rate of growth of the number of dentists. Recent years have shown that two further routes into the UK dental register have proved very attractive: dentists from within Europe, who enjoy freedom of movement, and those from the rest of the world via the overseas registration exam. Furthermore, the level of private care is shifting fast, new UK graduates are increasingly finding it difficult to get jobs in areas of their choice, and the historical flexibility in the system has reduced with devolved budgets for dentistry. Third, many of the assumptions such as the level of care provided for older people assume that the current level of demand is appropriate to need, whereas that is patently not the case for older people: uptake is low, barriers to dental care are multiple, ${ }^{43}$ and there is unmet need., ${ }^{2,4}$ Should these barriers be minimised, and this is clearly required as a matter of health policy, then uptake may increase at a faster rate than changes in tooth retention suggest. ${ }^{2}$ Fourth, in modelling for the future there is no consensus over what constitutes good care for older people and there is no evidence that the care provided under the old system, which encouraged a drill and fill approach, was appropriate for older people. Fifth, in undertaking the modelling exercise it was necessary to model the whole workforce, as older people's care is not limited to a section of dental care professionals but is provided by most of the workforce most of the time; hence the data are presented in relation to the workforce as a whole.

We need to have better data nationally to inform workforce planning on the overall supply of the dental workforce, following the Scottish approach. ${ }^{30}$ Given workforce mobility, there would be great merit in doing this UK-wide. The body best equipped to assist is the GDC. An annual audit in parallel with collection of fees would be really helpful in profiling the dental professions, identifying in which services they work, their roles, working patterns, systems of care and their status as generalists or specialists or DCPs. At a system level, we also need better data on what dental professionals are doing in the current NHS system and increasingly it will be important to collect information on skill-mix of performers in relation to clinical activity.

\section{Workforce shortfall}

All workforce planning exercises undertaken so far this century suggest a workforce shortage in relation to demand, particularly where this is linked to need. This project is no exception and parallels the findings in England where there is a reported shortfall, working towards a possible surplus in the third decade of this century. ${ }^{9}$ Furthermore, demand for care is reported as increasing by around $80 \%$ to 2028 and this compares favourably with the lower forecast of demand broken down by age-band in the English workforce review from between 31\% in the 65-74-year-olds to $150 \%$ for those aged 85 years and over for the first decade alone, ${ }^{9}$ with a further $30 \%$ and $50 \%$ respectively in the successive decade. So how do we square the reported shortfall in this paper with the suggestions that there are increasing pressures on getting jobs for new graduates in the dental care system? Some of this relates to resources and the lack of flexibility in the new system.

\section{Workforce skill-mix}

How much primary dental care could, and should, DCPs provide? Due to the uncertainty surrounding many of the model inputs and the numerous assumptions that had to be made, we refrain from recommending precise workforce numbers by staff type. DCPs clearly will not be able to provide all elements of care that are within their competency, either because patients are medically compromised and dentists need to provide their care, or because the course requires some complex elements and it is considered more cost effective for dentists to provide it all. Some recognition of this was built into the assumptions for hygienists/therapists, and also the fact that DCPs do not work as long hours as dentists. While it is possible, and desirable, to debate the detailed assumptions which supported this modelling, the findings of this study suggest that there is need for more dental staff time to be dedicated to the care of older people, and potential for use of skillmix with both hygienists/therapists and CDTs in the provision of care. The "skill-mix revolution' scenario explored maximum use of DCPs and suggests a drastic reduction in the dentist's role. While it may not be appropriate or advisable for this level of care to be delegated to DCPs, as many of 
these patients will have complex medical and social histories which add to the complexity of their care, it does highlight that increasing both the numbers and clinical roles of DCPs may be a positive contribution to dental care for older people, particularly when capacity needs to be increased. Ultimately, the potential capacity of DCPs should be increased and the dentists' roles in the team should be revised to one that is more appropriate to their knowledge, skills and leadership potential. ${ }^{45}$ This is an issue to be debated by the profession and policy makers to inform workforce education, supported by workforce modelling.

Observation of the status of dental care in the Netherlands may prove revealing given that since 2002 the nation has been training equal numbers of dentists and oral therapists due to the increasing demand for preventive and basic oral care only. ${ }^{46}$ In specific reference to dental care for older people, we recommend that steps are taken to allow clinical dental technicians to enter the British dental profession as soon as possible and make the necessary changes to NHS regulations to enable CDTs to undertake dental examinations and receive referrals from general dental practitioners.

Development of skill-mix requires the support and coordination of those involved in workforce education, including funders and health policy makers. Examples include ensuring that CDTs can be supported in their education and training and that there is a change in health policy to enable CDTs to become performers and providers in the NHS, empowered to make and accept referrals for care. Expansion of team working will require changes at practice level with facilities that support team working. Opportunities may be available in England for dental teams to be located in polyclinics, in line with the 'Next Stage Review' of the NHS in England by Lord Darzi. ${ }^{47}$

Ultimately we recommend that policy makers need to explore the challenges and benefits of implementing the optimal skill-mix workforce against the feasibility, practicality and desirability of doing so to meet population health needs.

\section{CONCLUSIONS}

The model suggests that with widening skill-mix, dental care professionals can play a major role in building dental care capacity for older people in future. There are significant implications for health policy, professional bodies and dental teamworking.

Competing interests: JEG was a member of the National Working Group for Older People. ${ }^{4}$

Authors' contributions: ERK undertook the research as her MSc Project. JEG advised on dental policy and modelling and PRH advised on technical modelling. JEG led on the design and content of this paper, to which all authors contributed. All three authors agreed the final version.

Acknowledgements: The authors wish to thank Dr David Davis, Chair of the National Working Group for Older People, and Mr Barry Cockroft, Chief Dental Officer for England, for providing access to the data from the Dental Practice Board. Thanks also to the staff of the Dental Practice Board for providing the dental data analysed in the study.

1. Office of National Statistics. Focus on older people: demographic profile. London: Office of National Statistics, 2005. http://www.statistics.gov.uk/.

2. Kelly M, Steele J, Nuttall N et al. Adult dental health survey: oral health in the UK 1998. London: Department of Health, 2000.

3. British Dental Association. Oral healthcare for older people: 2020 vision. London: British Dental Association, 2003

4. National Working Group for Older People. Meeting the challenges of oral health for older people: a strategic review. Gerodontology 2005 22(Suppl 1): 3-48.

5. Gallagher J E, Fiske J. Special care dentistry: a professional challenge. Br Dent J 2007; 202: 619-629.

6. Kleinman E R, Harper P, Gallagher J E. Trends in NHS primary dental care for older people in England: implications for the future. Gerodontology 2009; 26: 193-201.

7. NHS Executive. A health service of all the talents: developing the NHS workforce. A consultation document on the review of workforce planning. London: NHS Executive, 2000

8. Department of Health. NHS dentistry: options for change. London: Department of Health, 2002.

9. Department of Health. Report of the primary care dental workforce review. London: Department of Health, 2004.

10. Chief Dental Officer. NHS dentistry: delivering change. London: Department of Health, 2004.

11. General Dental Council. The registration of dental care professionals. London: General Dental Council, 2005

12. General Dental Council. Principles of dental team working. London: General Dental Council, 2006.

13. Lambert-Humble S. Opportunities for the dental team arising out of the new arrangements for primary dental care. Prim Dent Care 2005; 12: 15-19.

14. Allred $H_{1}$ Hobdell M. The planning and development of educational programmes for personnel in oral health. Report. Geneva: World Health Organization, 1986. Report no: 93. Contract no: ED273576.

15. Evans C, Chestnutt I G, Chadwick B L. The potential for delegation of clinical care in general dental practice. Br Dent J 2007; 203: 695-699.

16. Secretary of State for Health. Reforms with bite - 1000 more dentists by October 2005. London: Department of Health, 2004. Reference no: 2004/0265.

17. Powell N. Simulation and optimization of healthcare workforce need. Southampton: University of Southampton, 2006. PhD Thesis.

18. Flagle D. Some origins of operational research in health service operations. Oper Res 2002; 50: 52-60.

19. McManus / C, Livingston G, Katona C. The attractions of medicine: the generic motivations of medical school applicants in relation to demography, personality and achievement. BMC Med Educ 2006; 6: 11.

20. Harper P, Phillips S, Gallagher J. Geographical simulation modelling for the regional planning of oral and maxillofacial surgery across London. J Oper Res Soc 2005; 56: 134-143.

21. Burgersdijk $R$, Brokhurst $E$, Truin $G$ et al. Future scenarios on dental health care: a reconnaissance of the period 1990-2020. London: Kluwer Academic Publishers, 1994.

22. Schreuder R F. Health scenarios and policy making lessons from the Netherlands. Futures 1995; 27: 953-958.

23. Brenner M. Scenarios, decision making and strategic planning: a framework. In Brouwer J J L M (ed) Scenarios and other methods to support long-term health planning: theory and practice. pp 21-35. Utrecht: STG, 1986.

24. Longley $\mathrm{M}$, Warner $\mathrm{M}$. Future health scenarios strategic issues for the British health service. Long Range Planning 1995; 28: 22-32.

25. Minister for Health. More dentists now, more dentists later. London: Department of Health, 2005.

26. British Dental Association. Evidence to the doctors' and dentists' review body. London: British Dental Association, 2005.

27. Boulos M, Phillips G. Is NHS dentistry in crisis? 'Traffic light' maps of dentists distribution in England and Wales. Int J Health Geogr 2004; 3: 10

28. Department of Health. Primary care workforce review. London: Department of Health, 2004.

29. NHS Education for Scotland, ISD Scotland. Workforce planning for dentistry in Scotland. Edinburgh: NHS Education for Scotland, 2004

30. NHS Scotland. An update on the analysis and modelling of the dental workforce in Scotland. Edinburgh: NHS Scotland, 2006.

31. Try G. Too few dentists? Workforce planning 1996-2036. Prim Dent Care 2000; 7: 9-13

32. Hornby P, Stokes E, Russell W, Cochrane D, Morris J. Workforce review for the Midlands Strategic Health Authority. Br Dent J 2006; 200: 575-579.

33. Harper P R, Phillips S, Gallagher J E. Regional planning of oral and maxillofacial surgery services. J Oper Res Soc 2005; 56: 134-144.

34. Harper P R, Shahani A K, Gallagher J E, Bowie C. Planning health services with explicit geographical considerations: a stochastic location-allocation approach. Omega-Int J Manage Sci 2005; 33: 141-152.

35. Dental Practice Board. Dental statistics. Eastbourne: Dental Practice Board, 2005.

36. The Information Centre. NHS dental activity and workforce report. England: 31 March 2006. London: The Information Centre, 2006

37. Shaw C. 2004-based population projections in the UK and constituent countries. Population Trends 2006; 123: 9-20.

38. Kravitz A, Bearne A. The 1999 BDA Heathrow timings inquiry. Br Dent J 2000; 188: 189-194.

39. General Dental Council. Dentists register. London: General Dental Council, 2006.

40. Harper P R, Kleinman E R, Gallagher J E. Workforce planning for dentistry: optimising the dental team skill-mix for England cost-effectively. J Oper Res Soc submitted for publication.

41. Seward M. Better opportunities for women dentists. London: The Stationery Office, 2001.

42. Garrett M. Health futures handbook. Geneva: World Health Organization, 1999.

43. Borreani E, Wright D, Scambler S, Gallagher J E. Minimising barriers to dental care in older people. BMC Oral Health 2008; 8: 7.

44. Steele J, Lader D. Social factors and oral health in children. In Children's dental health in the UK, 2003. London: The Stationery Office, 2004.

45. Gallagher J E, Wilson N H F. The future dental workforce? Br Dent J 2009; 206: 195-199.

46. Eaton K. New dental school in SW England: a step in the right direction. Prim Dent Care 2006; 13: 47

47. Darzi A. High quality care for all: the next stage review. London: Department of Health, 2008. 